\title{
Identifying parameters for a performance-based framework: Towards prioritising underutilised historical buildings for adaptive reuse in New Zealand
}

\author{
Itohan Esther Aigwi $^{\mathrm{a}, *}$, Jason Ingham ${ }^{\mathrm{b}}$, Robyn Phipps ${ }^{\mathrm{a}}$, Olga Filippova ${ }^{\mathrm{c}}$ \\ ${ }^{a}$ School of Built Environment, Massey University, Auckland, New Zealand \\ ${ }^{\mathrm{b}}$ Department of Civil and Environmental Engineering, The University of Auckland, Auckland, New Zealand \\ ${ }^{\mathrm{c}}$ Department of Property, The University of Auckland, Auckland, New Zealand
}

\section{A R T I C L E I N F O}

\section{Keywords:}

New Zealand

Performance-based framework

Adaptive reuse

Historical buildings

Urban regeneration

Parameters

\begin{abstract}
A B S T R A C T
This paper identifies the parameters for a performance-based framework to prioritise underutilised historical buildings for adaptive reuse interventions, while discussing its effectiveness towards promoting sustainable and resilient urban areas in New Zealand.

A narrative review of extant literature is done to justify the need for the performance-based framework and build a list of relevant parameters that elucidates all or part of a typical decision-making process regarding the selection of historical buildings for adaptive reuse in New Zealand.

Five main priority aspects with significant evaluation criteria that have been identified from this study are economic sustainability, built-heritage preservation, socio-cultural aspects, building usability, and regulatory aspects. This paper's originality pertains to the development of parameters for a performance-based framework that offers a basis for relevant adaptive reuse stakeholders to prioritise underutilised historical buildings while balancing their diverse objectives. Accordingly, the performance-based framework has been validated to justify the relevance of its applicability to the different outlined parameters, towards prioritising underutilised historical buildings for adaptive reuse in New Zealand.
\end{abstract}

\section{Introduction}

A majority of historical buildings around the world are often viewed as assets that are essential for the development of local tourism, due to the heritage and socio-cultural values they possess (Bedate, Herrero, \& Sanz, 2004; Pedersen, 2002). These buildings play a crucial role in the socio-economic and cultural development of society (CPWD, 2013) by providing a physical link and progression of cultural evidence to the past (Goodwin, Tonks, \& Ingham, 2009). Most town centres in New Zealand typically feature old and vacant historical buildings. Although most of these buildings possess heritage values, a significant proportion of the buildings are underutilised (Yakubu et al., 2017). Accordingly, poor building conditions, socio-economic factors, and building regulatory requirements, have been identified as causal factors to the desertion and high vacancy rate of most historical buildings in New Zealand's provincial town centres (Aigwi, Phipps, Ingham, \& Filippova, 2019; Yakubu et al., 2017).

The increasing awareness that it is cheaper to convert older buildings for newer functions rather than abandoning them for demolition and reconstruction is one of the critical factors that have promoted the vast interest in the adaptive reuse strategy (Aigwi, Egbelakin, \& Ingham, 2018; Ball, 2002; Bullen \& Love, 2011a; Pearce, DuBose, \& Vanegas, 2004). Some studies have identified cases and concepts, with implications suggesting that performance upgrading of heritage buildings through adaptive reuse create tremendous influences on the sustainable development of a built environment (Bromley, Tallon, \& Thomas, 2005; Plevoets \& Van Cleempoel, 2019; Rohracher, 2001). In a quest to minimise the socio-economic costs of developing a sustainable and resilient urban area, and, the environmental cost of demolition, the adaptive reuse approach becomes beneficial to the government, communities, building owners/investors, and developers in realising that an essential aspect of any successful urban regeneration strategy is the reuse of heritage buildings (Ball, 1999; Wilkinson \& Osmond, 2018; Yakubu et al., 2017).

While promoting sustainable and resilient urban areas through the retention of historical buildings, some trade-offs may exist among

\footnotetext{
* Corresponding author.

E-mail address: i.aigwi@massey.ac.nz (I.E. Aigwi).
} 
relevant decision-makers. These trade-offs need to be balanced among the respective adaptive reuse decision-making stakeholders who may have both direct and indirect interests in reusing underutilised historical buildings (Aigwi, Phipps, Ingham, \& Filippova, 2020). Since these relevant stakeholders may have a common urban regeneration goal, but diverse opinions about the adaptive reuse approach, various factors based on their different perceptions on the adaptive reuse approach will need to be considered and deliberated upon, hence making the decision-making process very difficult (Wang \& Zeng, 2010). Although some adaptive reuse decision-making tools have been recognised from other studies (Caccavelli \& Gugerli, 2002; Conejos, Chew, \& Yung, 2017; Geraedts \& Van der Voordt, 2007; Langston \& Shen, 2007; Langston \& Smith, 2012; Love \& Bullen, 2009; Wilkinson, Remøy, \& Langston, 2014), the necessity for yet another tool to prioritise optimal building alternatives, while balancing the diverse interests of adaptive reuse stakeholders (Aigwi et al., 2020) in an urban regeneration decision-making setting is essential.

\section{Objective and literature review}

This paper aims to identify relevant parameters for a performancebased decision-making framework to prioritise the most suitable historical building options for adaptive reuse interventions in New Zealand. A narrative literature review is done to synthesise a comprehensive description of existing adaptive reuse decision-making models to identify inconsistencies in knowledge (Baker, 2016; Green, Johnson, \& Adams, 2006; Machi \& McEvoy, 2016; Onwuegbuzie \& Frels, 2016), and hence, facilitate the formation of relevant parameters for the development of the proposed performance-based framework.

\subsection{Adaptive reuse and its impacts on fostering sustainable and resilient urban areas}

The adaptive reuse approach focuses on changing the use of an existing building to enable it to function as a contemporary building while preserving its useful and valuable features (Ball, 2002; Shehata, Moustafa, Sherif, \& Botros, 2015). Hence, this change of use process involves the conservation and reuse of functionally obsolete or old underutilised historical buildings for new and more appropriate functions. The concept of adaptive reuse implies: changing an existing building's original use to serve new functions (Douglas, 2006); retaining the original features and structure of an existing building (Love \& Bullen, 2009); or extending the useful life of an existing building (Mansfield, 2002; Wong, 2017).

From an economic point of view, it is often cheaper and faster to redevelop historical buildings through adaptive reuse, when compared to demolition and rebuild (Aigwi et al., 2018; Bullen \& Love, 2011b; Douglas, 2006; Heath, 2001; Langston \& Shen, 2007), except in situations that may require total structural reconstruction of the buildings which could be labour-intensive (Shipley, Utz, \& Parsons, 2006). Consequently, when applying the adaptive reuse approach to redevelop a specific floor area of an existing building, it is noted that it could take about half the time required to demolish and rebuild the same floor area of a new building from scratch (Larkham, 2002). This reduced timeframe implies that there will be a corresponding reduction in the financing costs and the impact of inflation on the overall construction, leading to a minor interruption of cash flow from tenants (Highfield \& Gorse, 2009; Langston \& Shen, 2007). Also, since most of the existing building's structural components are already in place to serve as raw materials for adaptive reuse, and the contract periods are typically shorter than that of the rebuild, the borrowing cost for the redevelopment projects are usually minimised (Shipley et al., 2006). Past studies have also recognised adaptive reuse as a viable option towards improving the economic situation of an urban area through an increase in property values of adapted historical buildings (Chau, Wong, Leung, \& Yiu, 2003; Yau, Wing Chau, Chi Wing Ho, \& Kei Wong, 2008; Yiu \&
Leung, 2005).

Nevertheless, some indirect costs which may be encountered in the adaptation process, such as regulatory requirements, structural complexities of historical buildings projects (Bullen, 2007; Kohler \& Yang, 2007; Wilkinson, James, \& Reed, 2009), and environmental cost of demolition waste (Yuan, Shen, Hao, \& Lu, 2011), may weaken the adaptive reuse economic argument when compared to the cost of a new building. In addition, some renovations could be more labour-intensive compared to new constructions, especially when an adapted historical building is protected through legislation as a heritage building that requires the restoration of certain heritage features (Aigwi et al., 2020). Accordingly, in such situations, renovations could be more expensive, and even worse in times and regions where labour costs are higher than the cost of materials (Shipley et al., 2006). Although the process of identifying the value for money for adaptive reuse implementation is mostly linked to monetary return, focusing on only financial matters may likely introduce bias into an adaptive reuse decision-making process (Langston, Wong, Hui, \& Shen, 2007).

While minor precedence is often given to the socio-cultural impacts of adaptive reuse during reuse deliberations (Bullen \& Love, 2011a), socio-cultural aspects have been highlighted as key to achieving successful urban regeneration strategies (Misırlısoy \& Günçe, 2016a). A most suitable new use for an underutilised historical building should have the capacity to meet the immediate needs of a local community and improve the quality of lifestyle of its people. Improving the quality of lifestyle for the residents of an area would contribute to enhancing the significance of place through a sustained societal life (Engelhardt, Unakul, \& Endrina, 2007). Adaptive reuse of historical buildings has been found to promote the preservation of core heritage values of the buildings, hence, retaining attractive streetscapes that would add character and sense of place to host communities (Bullen, 2007; Langston \& Shen, 2007). Built heritage preservation through adaptive reuse has also been suggested as practically sustainable concepts for urban regeneration planning (Alpopi \& Manole, 2013; Nasser, 2003). Also, while the benefits of adapting historical buildings have been found to promote built heritage preservation (Aigwi et al., 2018; Plevoets \& Van Cleempoel, 2011, 2019), some other studies have stressed on the success of the new adapted functions concerning local community development, as essential adaptive reuse goals (Douglas, 2006; Shehata et al., 2015). Accordingly, a substantial reduction in the number of vacant historical buildings in an area through adaptive reuse would potentially create a more vibrant community that could enjoy an improved quality of life from the socio-cultural viable new use of the buildings (Yakubu et al., 2017).

From an environmental stance, the process of adapting historical buildings for new uses promotes sustainable communities through the significant reduction in building materials and energy consumption, and reduced pollution $\left(\mathrm{CO}_{2}\right.$ emission) from construction activities (Itard \& Klunder, 2007), while maintaining the unique characteristics, and retaining the cultural identity of the buildings (Boarin, 2016). Since all buildings, including historical buildings, contain embodied energy, reusing the functionality of existing buildings, their components, and salvaged materials would help conserve this energy (Binder, 2003). Also, the adaptive reuse process has been noted to be a better way to minimise the impact of environmental interruptions from ground contamination, dust, hazardous and falling materials, when compared to new construction activities (Bullen \& Love, 2010). The impact of these environmental interruptions could cause detrimental interference to the existing ecosystems, hence, causing degradation of natural habitats and biodiversity of species (Koren \& Butler, 2006). Nevertheless, it has been argued that the practicality of meeting regulatory requirements of indoor air quality, acoustic and thermal performances of historical buildings through adaptive reuse, may not be entirely achievable due to the dependence of the adaptive reuse process on the usability and required end use of the building (Wilkinson et al., 2009). Although the environmental performance of an adapted historical building may not 
entirely match that of a newly constructed building, its social gains could balance this drawback (O'Donnell, 2004). Also, since most historical buildings do not usually promote passive environmental systems, the adaptive reuse approach could provide an opportunity to try out different innovative technologies, towards developing diverse solutions to promote sustainable development (Bullen, 2007).

Additionally, in active seismic regions, the adaptive reuse concept could be considered a feasible approach to promote seismic resilience in high seismic hazard areas, when applied to earthquake-prone historical buildings (Aigwi et al., 2018). In New Zealand for instance, since most change of use alterations would trigger the seismic retrofit requirements of earthquake-prone buildings (EPBs) if the value exceeds $25 \%$ of the building's ratable value (MBIE, 2016), the adaptive reuse process could serve as a useful approach to motivate building investors to upgrade historical EPBs, towards the development of seismic resilient communities.

\subsection{Situations faced by decision-makers during adaptive reuse project prioritisation deliberations}

Typical situations encountered by adaptive reuse decision-makers are discussed in detail to determine relevant attributes and factors to be deliberated upon in the process of selecting optimal historical building alternatives for adaptive reuse interventions.

During adaptive reuse debates, it is essential to consider the reuse potentials of historical buildings in ways that would be socio-economically viable to their local community. According to Murtagh (2006), firstly, an evaluation of the potential property market and location characteristics must be done by answering the following questions: (i) is there an oversupply of underutilised historical buildings? (i) is there adequate demand for the proposed new use? (ii) how strategic is the location of the historical building to be reused? (iii) is the location easily accessible to services such as transportation and parking facilities? (iv) How can the social and demographic character of the local area impact the feasibility of the reuse project? (v) what type of local development is ongoing, and who are the competitors? (vi) what is the current or prospective environmental quality of the historical building's surroundings? (vii) What kind of uses exists within other surrounding buildings?

Also, the building characteristics of the historical buildings are analysed in terms of the physical conditions of the buildings, historical and architectural features, and how these buildings comply with relevant regulatory requirements. Accordingly, the following questions should be addressed (Wang \& Zeng, 2010): (i) how stable are the structural elements, and what is the existing condition of the nonstructural elements of the buildings? (ii) do the buildings have a significant amount of architectural and historical fabric that meets the criteria of the national heritage register? (iii) how feasible is it for the buildings to preserve the heritage fabric? (iv) Would existing regulatory (i.e., building code, seismic, planning, and zoning, heritage, health and safety, fire, disability) requirements permit the potential new use of the buildings? All these questions need to be deliberated upon by the stakeholders during the adaptive reuse decision-making process.

Furthermore, while conducting a stakeholder analysis for pertinent actors of the adaptive reuse decision-making process to understand their background and roles for transparency and coherence of the process, the actors are classified under four categories of stakeholders (i.e., investors, producers, regulators, and users). As the investors (i.e., private building owners, developers or government) may mostly be concerned about the return on investment, the government in this context play an important role by creating stimulus through planning regulations that will promote the adaptive reuse projects. Besides, the producers (i.e., building professionals such as architects, engineers, heritage restoration experts, quantity surveyors, project managers, etc.) who bear most of the risk from other stakeholder groups may be most concerned about timing, clarity, and closure of the entire reuse process.
While the role of regulators (i.e., health and safety, heritage, seismic code, planning and zoning compliance officers) is to ensure that producers maintain strict compliance with relevant regulatory procedures, the users (i.e., tenants, leaseholders, and public) may be most concerned about enhanced reuse strategies by representing demand either directly or indirectly.

There is, therefore, a need to identify the parameters of a framework that can be used to weigh the above-highlighted situations faced by decision-makers during adaptive reuse project prioritisation deliberations, in order to balance their differing interests while selecting optimal historical building alternative from a pool of historical building options.

\subsection{The performance-based planning approach for adaptive reuse decision- making}

Performance-based planning involves the application of performance trends to promote the strategic development of significant longrange plans and activities in a manner that would guaranty efficient and effective outcomes (Frew, Baker, \& Donehue, 2016). The application of performance-based planning approach is prevalent within the public sector as a means to improve desired urban collaborative decisions with the use of evaluation-based techniques (Aigwi et al., 2019; Baker, Sipe, \& Gleeson, 2006). Some developed countries such as New Zealand, Australia, the USA and Great Britain have successfully applied performance-based planning approaches to enhance decision-making in natural resource planning relating to building regulations and land use planning (Frew et al., 2016). As a result, the basis for the development of a performance-based planning approach is usually on the impact of land use as a function of its physical intensity and features, rather than traditional zoning impacts on land use (Baker et al., 2006).

When applying the performance-based planning ideology to an adaptive reuse decision-making setting, predetermined criteria and priority aspects can be evaluated in a subjective manner to set quantitative boundaries on acceptable adaptive reuse standards (Aigwi, Egbelakin, et al., 2019). Accordingly, the core components of the performance-based planning approach relating to adaptive reuse decisionmaking should include the criteria and priority aspects that would describe in detail an effective and efficient adaptive reuse outcome, and a methodology to describe the influences of acceptable measurement standards on the desired adaptive reuse outcome (Aigwi, Egbelakin, et al., 2019). Performance-based planning approaches should, therefore, be explored by adaptive reuse decision-makers to promote urban resilience through the retention of historical buildings.

\subsection{Review of some existing adaptive reuse decision-making toolkits and frameworks}

The purpose of this narrative literature review is to establish if efforts have been made to identify relevant parameters to prioritise optimal building options from a list of vacant historical building alternatives for adaptive reuse interventions towards a sustainable and resilient urban regeneration. Various frameworks have been advanced towards assisting decision-makers in assessing the complexities around making best decisions regarding the adaptive reuse potentials of existing buildings (Caccavelli \& Gugerli, 2002; Conejos et al., 2017; Geraedts \& Van der Voordt, 2007; Langston \& Shen, 2007; Langston \& Smith, 2012; Love \& Bullen, 2009; Wilkinson et al., 2014).

Caccavelli and Gugerli (2002), developed the TOBUS decisionmaking tool to prioritise and select the best retrofit solutions and cost estimation for individual existing office buildings. The TOBUS framework was developed for the owners of office buildings, construction professionals and real estate investors, to analyse the indoor environmental quality, energy consumption, physical state and functional obsolescence of the buildings' elements and services. Although the design of the TOBUS allows its users to address professional and multi- 
disciplinary problems associated with the refurbishment of buildings, it targets only office buildings. In a similar study, (Love \& Bullen, 2009), examined the use of NABERS (National Australian Built Environment Rating System) to assess the influence of occupants behaviour on the environmental performance of adapted commercial buildings. Accordingly, the underlying parameters and methodologies of both the TOBUS and NABERS frameworks fall outside the scope of this paper study because they: (i) are incapable of prioritising and ranking most suitable historical buildings from a group of alternatives for adaptive reuse intervention; and (ii) do not consider economic, socio-cultural, heritage preservation, and usability values of the existing buildings. Moreover, although the addressed environmental aspects in the TOBUS and NABERS frameworks are important, the occupant's survey and checklist methodologies are unable to deal with subjective views of all relevant stakeholders involved in an adaptive reuse decision-making process, while balancing their diverse interests.

Another study conducted by Langston and Smith (2012), led to the development of the iconCUR framework which applies the MCDA weighted matrix method to map performance scores of built assets in 3D space and identifies the best course of property decision action to pursue over time. The iconCUR framework practically demonstrates the ability of mapping both decision criteria (e.g., building condition, utilisation, and reward) and sub-criteria (e.g., mutual utility and stakeholder concern), with attributes (e.g., regulatory compliance, design standard, and sustained service level) and alternatives (e.g., retain, renovate, reuse, or reconstruct). Likewise, Geraedts and Van der Voordt (2007) presented a checklist - Transformation Meter, to support adaptive reuse decision-makers on whether or not to start a transformation process of reusing empty office spaces as residential dwellings. The application of the Transformation Meter to investigate the potential of transforming existing office buildings into residential spaces is done by conducting the following steps on case study buildings: (i) quick scan; (ii) market feasibility and location characteristics scan; (iii) transformation class determination scan; (iv) financial feasibility scan; and (v) risk assessment scan

Baker, Moncaster, and Al-Tabbaa (2017) examined five UK case studies to ascertain why decisions on whether or not to reuse or demolish underutilised existing office buildings are made. Their findings were assessed against decisions produced by both the iconCUR framework and Transformation Meter decision-making tools. Accordingly, it was revealed that although the two theoretical decision support tools assessed 18 out of the 19 office buildings across the five case studies to have moderate to excellent transformability potentials, in reality, only 9 out of the 19 buildings were demolished. The reasons for the demolition were specified to be beyond the scope of the theoretical frameworks. In conclusion, the study highlighted that although the iconCUR framework and Transformation Meter decision-making tools were suitable for their proposed use, significant adjustments still needed to be made when applying them for different uses, or on masterplan sites (Baker et al., 2017).

Furthermore, the ARP (adaptive reuse potential) model was developed to identify and evaluating the embedded physical life of obsolete historical buildings at any point of the buildings' life cycle, to establish a right timing for adaptive reuse intervention on buildings (Langston \& Shen, 2007). This method is capable of transforming traditional adaptive reuse decision-making procedures to better sustainable strategies, practices, and outcomes. Moreover, the application of the ARP method to evaluate the embedded physical life of historical buildings requires the estimated present age (in years), and the projected physical life (in years) of the buildings. Some obsolescence factors (i.e., economic, social, functional, physical, technological, and legal) of the buildings are also required to evaluate the adaptive reuse potential of historical buildings because of their negative impact of reducing the useful life of the buildings. A similar study was conducted by Conejos et al. (2017) on the basis of the ARP model for developing the AdaptSTAR model, which is a subjective checklist of adaptive reuse design plans. The purpose of the AdaptSTAR model was to establish the consideration of adaptive reuse in the initial design process of new buildings, towards maximising future adaptability of existing buildings. However, the methodologies of both the ARP and AdaptSTAR models are not suitable for the study discussed in this paper because they both require continuous monitoring of new buildings and expert assessment of obsolescence factors in individual buildings.

Ferretti, Bottero, and Mondini (2014) explored the application of the Multi-Attribute Value Theory (MAVT) in a decision-making process to choose the best performing industrial historical buildings for touristic adaptive reuse purposes in Italy. Although the findings revealed the efficiency of the MAVT technique in choosing the most suitable industrial historical buildings to be adapted for touristic purposes, the use of expert panels was identified as the major limitation for the framework development.

This study is therefore timely as it identifies parameters for a framework to prioritise optimal building alternatives from a group of underutilised inner-city commercial historical buildings for adaptive reuse interventions while balancing the diverse interests of relevant stakeholders involved in an urban regeneration decision-making process in New Zealand. This knowledge gap has enabled the authors of this paper to form a list of priority aspects and measurement criteria for the development of the proposed performance-based framework.

\section{Research methodology}

This study focuses on identifying parameters for the development of a performance-based framework to prioritise optimal historical building alternatives during adaptive reuse decision-making processes in New Zealand. To achieve this aim, the qualitative research approach through a narrative literature review was conducted to create a comprehensive account of existing adaptive reuse decision-making models.

A narrative literature review is a comprehensive and critical analysis of existing knowledge on a research topic, usually done to establish a theoretical focus or context for the topic (Baker, 2016; Green et al., 2006; Machi \& McEvoy, 2016; Onwuegbuzie \& Frels, 2016). Knowledge gaps identified from this study's narrative literature review facilitated the formation of parameters applicable to the development of the proposed performance-based framework. The performance-based framework has been validated with the use of a focus group workshop encompassing decision-makers ranging from owners/developers/users of historical buildings, building professionals, to heritage, legal, and council/community representatives (Aigwi, Egbelakin, et al., 2019).

\subsection{Definition of priority aspects and criteria for the performance-based framework}

The proposed performance-based framework presents five focal aspects (i.e., economic sustainability, built heritage preservation, sociocultural aspects, building usability, and regulatory aspects), which are measured by relevant criteria 'see Table 1'. These priority aspects, relevant to assessing the reuse potential of heritage buildings towards building sustainable and resilient urban areas, are discussed below.

\subsubsection{Economic sustainability}

Potential new use for an underutilised historical building should be able to stimulate a buoyant economy for the host community. It is also expected that the successfully adapted building will have the capacity to generate enough profit that will be used for its future self-sustenance (Douglas, 2006). Besides, economic efficiency is also attained, where the tangible and intangible benefits of reuse projects outweigh the overall cost (i.e., capital regeneration cost, future running cost, and maintenance cost) of the projects (Orbasli, 2002). According to Engelhardt et al. (2007), the following factors have been suggested to be used as indicators when measuring the economic benefits of successfully adapted projects: (i) the numbers of newly established 


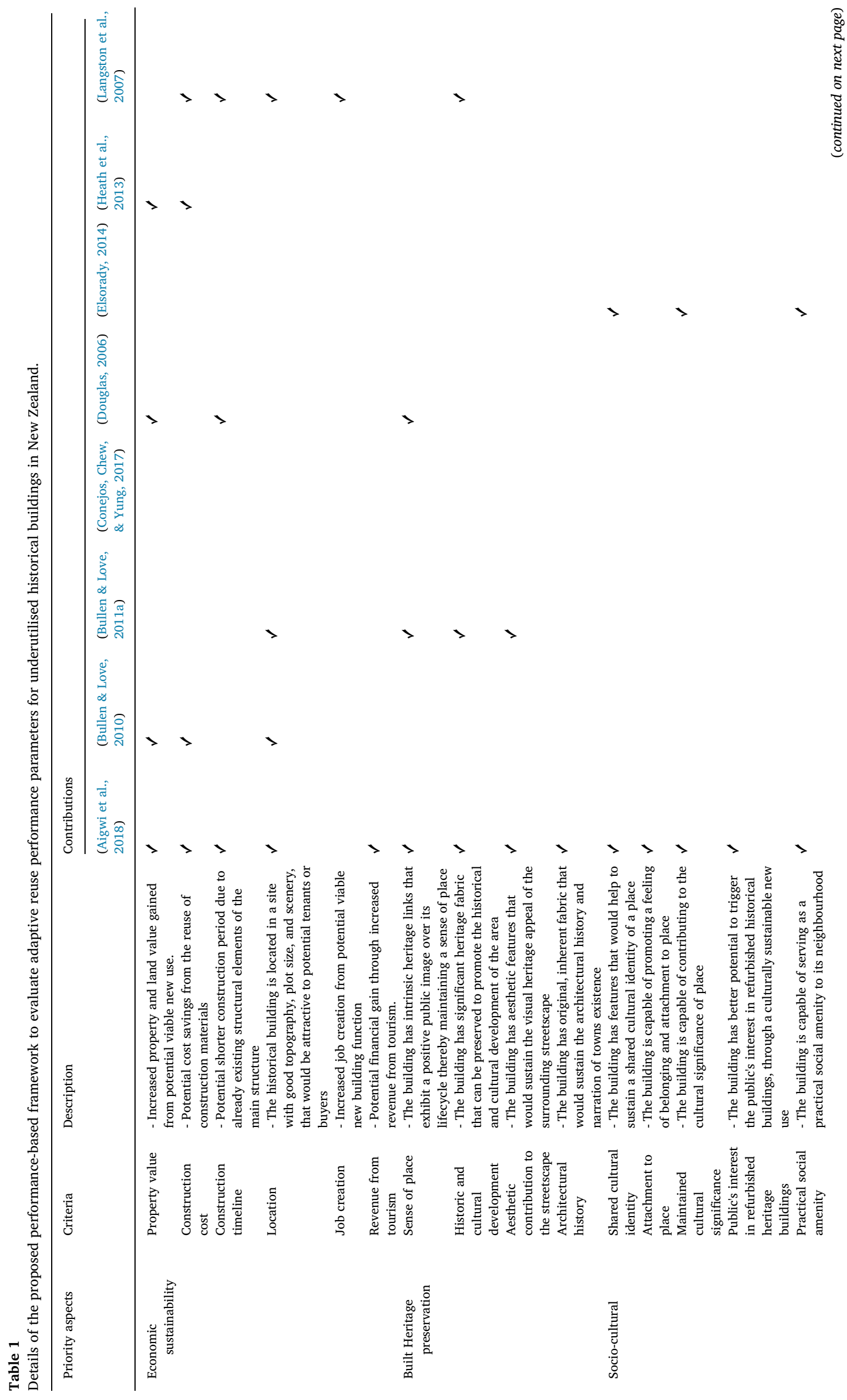




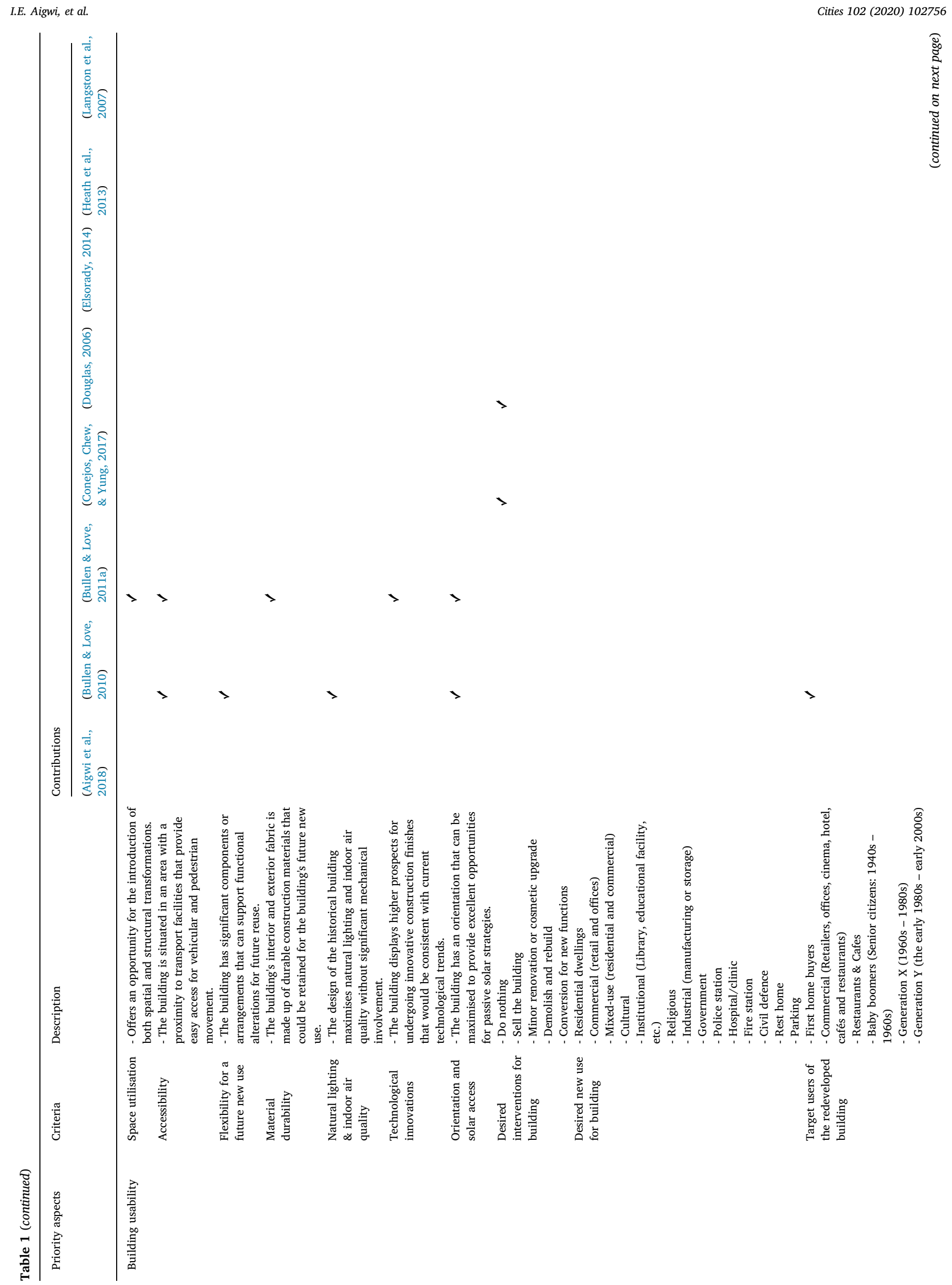



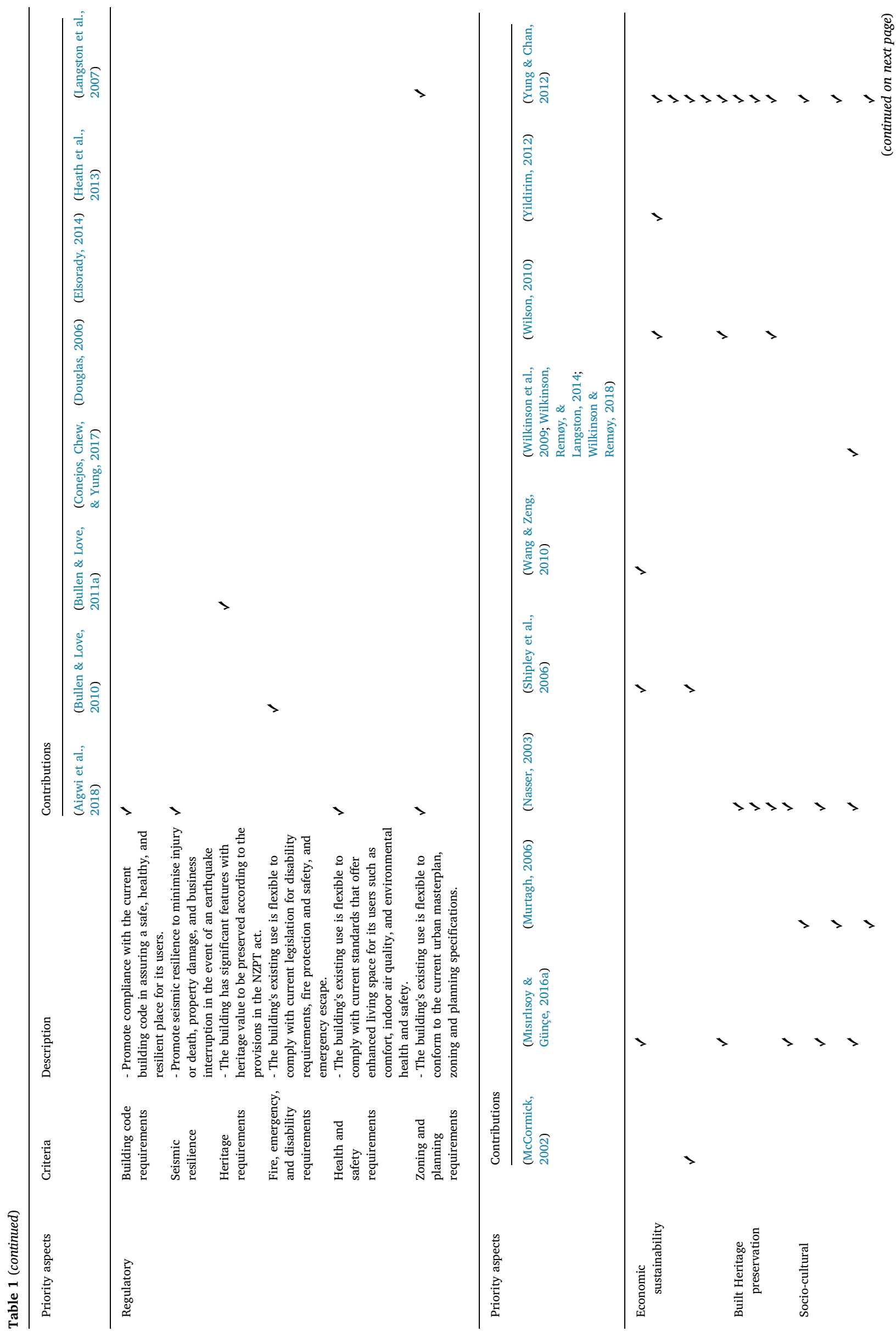
businesses and employment prospects for the local workforce, the increased value of surrounding properties, and the increased revenue from tourism for local businesses. Accordingly, other studies have identified a tremendous increase in the economic value of land and property, gained through the commercially viable new use of most adapted historical buildings (Heath, Oc, \& Tiesdell, 2013; Misirlısoy \& Günçe, 2016a; Wang \& Zeng, 2010). The increase in the economic value of the adapted buildings will eventually transfer to other surrounding properties with time, just like a ripple effect (Cook \& Thomas, 2003). For heritage buildings, this chain reaction could also boost potential financial gain through increased from cultural tourism in the area (Gravagnuolo, Angrisano, \& Fusco Girard, 2019; Gravagnuolo, Girard, Ost, \& Saleh, 2017), as visitors would be attracted to the area because of its attractive streetscape, and collection of revitalised historical buildings. An adapted historical building in a site with good topography, plot size, and scenery, will be attractive to potential tenants or buyers due to its location potentials.

Additionally, potential savings from the reuse of construction materials (Aigwi et al., 2018; Bullen \& Love, 2010; Langston et al., 2007; Yildirim, 2012), shorter construction period due to already existing structural elements of the main structure (Douglas, 2006; Yung \& Chan, 2012), and potential job creation from a viable new building function (Heath et al., 2013), are identified as useful economic indicators to measure the performance levels of successfully adapted historical buildings.

\subsubsection{Built heritage preservation}

Some heritage preservation charters, push for the architectural and heritage character of historical buildings to be preserved during maintenance and redevelopment interventions, to promote sustainability (ICOMOS, 1931, 1964, 2013, 2019). Given that, the mandate on heritage preservation has led to the scheduling of several heritage buildings into district plans, thereby protecting them from unsympathetic alterations or demolition through regulations. Other heritage and sustainable development charters have given the following conditions to be met before a historical building can be modified for reuse (NSW \& RAIA, 2008; UNESCO, 2009). Accordingly, the new use should (i) have a minimal impact on the building's heritage significance and background; (ii) be able to add a compatible and contemporary meaning that can provide value for future generations; (iii) enhance the spirit of a place; and (iv) conserve the culturally significant fabric of the building.

In active seismic parts of the world, earthquake-prone historical buildings with heritage values are viewed as public goods (Navrud \& Ready, 2002). These buildings have been surveyed to provide physical links and the progression of cultural evidence to the past (Goodwin et al., 2009). It is of the essence to preserve these earthquake-prone historical buildings through reuse because of their intrinsic heritage links that exhibit a positive public image over their lifecycle, thereby maintaining a sense of place (Aigwi et al., 2018; Douglas, 2006; Yung \& Chan, 2012). Moreover, built heritage preservation through adaptive reuse has also been suggested to promote the sustainable historical and cultural development of urban areas through the conservation of significant heritage fabric (Bullen \& Love, 2011a; Langston et al., 2007; Nasser, 2003). Accordingly, the visual heritage appeal of streetscapes with a significant number of reused historical buildings will be sustained through reuse, due to the aesthetic contribution of the buildings to the streetscapes (Wilson, 2010). Also, the architectural history and narration of a community's existence are sustained, due to the preserved original, inherent fabric of reused historical buildings (Misirlisoy \& Günçe, 2016a).

\subsubsection{Socio-cultural aspects}

Socio-cultural aspects usually incorporate the impacts of a historical building's new use to its local area through promoting the quality of lifestyle and exposure enjoyed by residents within the community 
(Langston et al., 2007). The cultural diversity and communal life in the area are also sustained (Mısırlısoy \& Günçe, 2016a). While serving as shared memory, a successfully adapted historical building will help to link residents to their roots, with which they can all reflect on as a collective cultural identity (Butina-Watson \& Bentley, 2007; Murtagh, 2006). As well, an adapted historical building is capable of providing a practical social amenity to its neighbourhood, revealed through improved social relationships, trust, support, and connectedness among residents (Elsorady, 2014).

Moreover, the new use of a repurposed historical building should be able to attend to the immediate needs of the local community (Engelhardt \& Rogers, 2009). Accordingly, general satisfaction in the new use of a historical building is capable of providing users with a feeling of belonging and attachment to place (Aigwi et al., 2018). However, socio-cultural aspects are often less prioritised for adaptive reuse projects, possibly because they are believed to be challenging to measure (Misırlısoy \& Günçe, 2016b). Hence, to achieve successful adaptive reuse projects repurposed historical buildings should be socioculturally justifiable.

\subsubsection{Building usability}

While focusing on the perspective of the end-users (or the public), building usability is a very much neglected aspect of measuring building performance (Jensø, Hansen, \& Haugen, 2004). In understanding and applying the concepts of building usability (or functionality in use) within the adaptive reuse context, all aspects of the stakeholders' expectations regarding the selection of most suitable adapted historical buildings are considered (Alexander, 2006). The definition of building usability suggests three main determinant factors (Arge, 2004): (i) effectiveness (i.e., is the proposed building perceived to be fit for its intended new use?); (ii) efficiency (i.e., how long will it take to implement the new use?); and (iii) satisfaction (i.e., what is the attitude of the end-users towards the intended new use?). A British study investigated the concept of building usability by assessing the contributions of building adaptability, usefulness, functionality in use, accessibility, flexibility, and ease of use, towards outlining the effectiveness, efficiency, and satisfaction of a building's new use (Alexander, Huovala, \& Kaya, 2003).

The theoretical principle of applying building usability within the adaptive reuse approach underlines that usability cannot be measured without enquiring for whom, and the usefulness for which an intended new purpose is for. The notion of an adaptive reuse decision-making process, where all relevant stakeholders are brought together within a given time frame, implies the uncertainty of actions maintained by the transparent and coherent nature of compromises sorted out between the actors. Given that, the nature of these compromises consider both the suitability of the opportunity used to attain the result, and also, other objectives of the actors (Alexander, 2006). Following the above theoretical development of building usability, it can be argued that building usability is realised through the interaction between the intended reuse of the buildings, and the perceived user experience, design and organisation processes.

Accordingly, for the performance-based framework development, the building usability priority aspect is measured under four main criteria with sub-parameters to be deliberated upon by all relevant stakeholders in the adaptive reuse decision-making process to select most suitable historical building alternative:

(i) what is the desired intervention for new use (Baker et al., 2017; Wilkinson \& Remoy, 2011)?

\footnotetext{
- Do nothing?

- Sell the building?

- Minor renovation?

Demolish and rebuild?

- Convert for new use?
}

(ii) what is the most suitable target use for the building alternatives (Wilkinson et al., 2009; Wilkinson et al., 2014)? (e.g., residential dwellings, or commercial - i.e., retail, offices, cinema, hotel, cafes, restaurant, or public space, or mixed-use - i.e., residential and commercial, or cultural - i.e., arts centre, or institutional - i.e., library, educational facility, or religious, or industrial - i.e., manufacturing or warehouse, or government use, or public toilet, or police station, or hospital/clinic, or fire station, or civil defence centre, or aged rest home, or parking space?);

(iii) who are the target users (Wilkinson et al., 2014)? (Such as first home buyers, or commercial purposes, or cultural groups, or educational institutions, or religious groups, or manufacturers, or government, or health sector, or students, or baby boomer generation, or generation-x, or generation-y?); and

(iv) what is the desired optimal functionality in use (Baker et al., 2017; Douglas, 2006; Wilkinson \& Remøy, 2018)? (i.e., offers a better opportunity for both spatial and structural transformations, or is situated in an area with a proximity to transport facilities that provide easy access for both vehicular and pedestrian movement; or has significant components or arrangements that can support functional alterations for future reuse, or the building's design maximises natural lightening and indoor air quality with lesser mechanical involvement, or the building displays higher prospects for undergoing innovative construction finishes that would be consistent with current technological trends, or the building has an orientation that can be maximised to provide excellent opportunities for passive solar gains?).

\subsubsection{Regulatory aspects}

It is crucial for decision-makers to consider all regulatory aspects of historical buildings when prioritising a list of these buildings to select the best alternative for adaptive reuse intervention. According to Mason (2009), it is expected that these regulatory aspects should be able to help accomplish a building's functional, socio-cultural, economic, and environmentally sustainable development goals when weighing up most suitable historical building options for reuse. Accordingly, an optimal historical building alternative should be able to comply with the current building code in guaranteeing a safe, healthy, and resilient place for its users (Wang \& Zeng, 2010). Also, the existing use of the building should conform to the current urban masterplan, zoning and planning specifications.

Furthermore, when considering seismic resilience in the case of historical buildings in active seismic areas, it will be essential to consider the compliance level of the buildings to seismic retrofit requirements put in place to minimise injury or death, property damage, and business interruptions in the event of an earthquake. Other regulatory requirements put in place to preserve the heritage features of the historical buildings should also be adhered to. Moreover, the existing use of an optimal selection should be able to comply with current standards that promote enhanced living spaces for its users, such as comfort, indoor air quality, and environmental health and safety. Finally, regulations regarding disability requirements, fire protection and safety, and emergency escape should not be left out as well.

\section{Results and validation}

Findings from the literature review led to the development of a performance-based framework. See Fig. 1 for the design logic of the framework, which involves a data collection system that integrates the global urban resilience and heritage retention concepts within the New Zealand context through provincial case study collaborations. Also, the performance-based framework has been validated through a focus group workshop interface that was aimed at testing stakeholders' visualisation and assessment of integrated multi-criteria adaptive reuse and town centre regeneration priority aspects, through iterative weighting and scoring scenarios (Aigwi, Egbelakin, et al., 2019). 


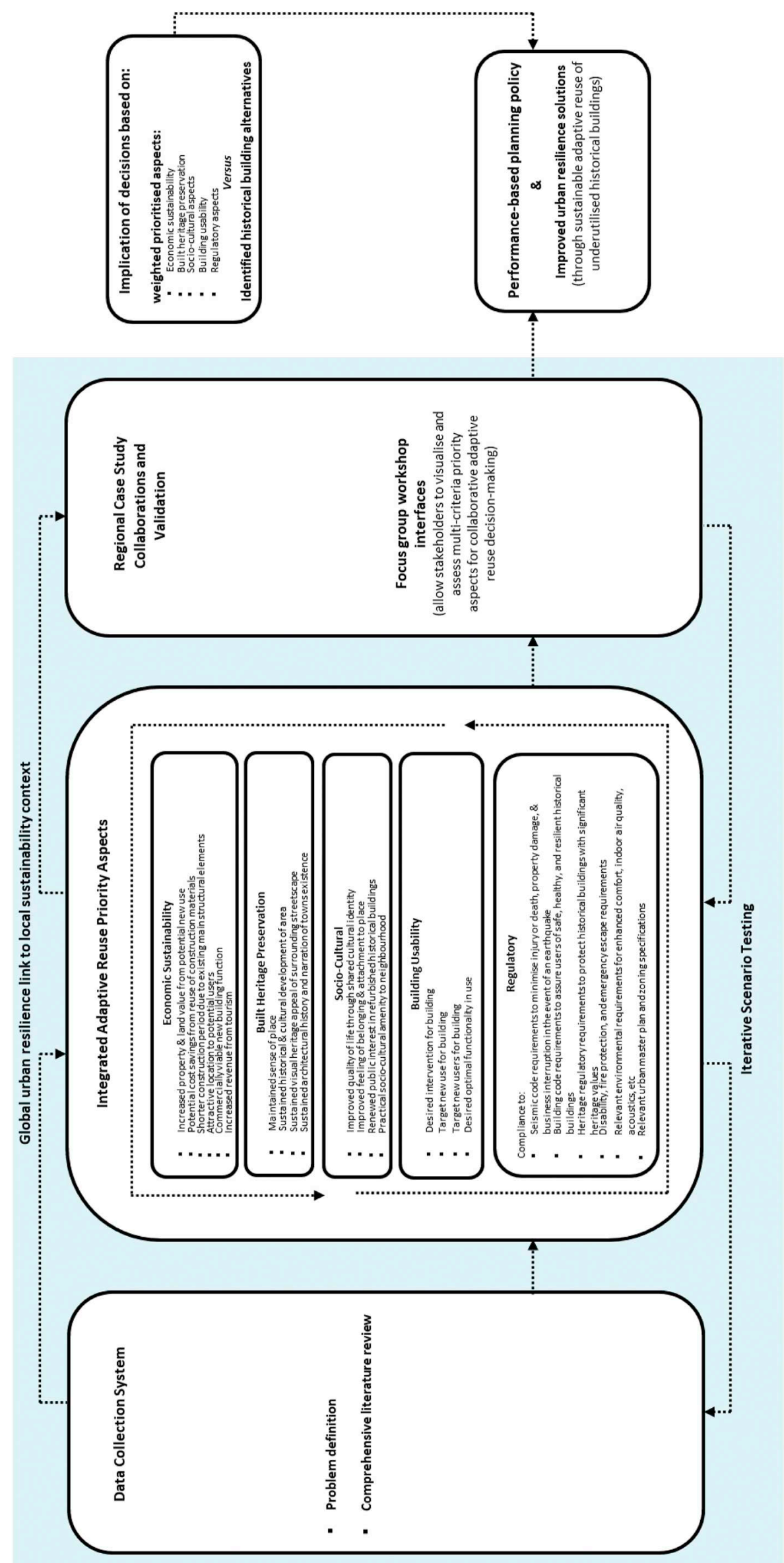

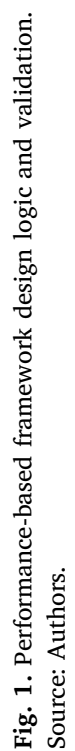


Accordingly, the implication of decisions based on the weighted priority aspects was evaluated against identified historical building alternatives to achieve performance-based planning outcomes and improved urban resilience solutions through the sustainable reuse of underutilised historical buildings (Aigwi, Egbelakin, et al., 2019).

\section{Discussion}

This paper identifies crucial adaptive reuse concerns necessary for evaluation by adaptive reuse stakeholders (Aigwi et al., 2020) through the formative phases of adaptive reuse decision-making deliberations so that determinations towards achieving sustainable and resilient urban areas can be enhanced. Table 1 provides details of the performancebased framework's five priority aspects for evaluating the adaptive reuse performance parameters for historical buildings. Each priority aspect represents distinctive significances, which, when combined, brings about a holistic synthesis of the framework for adaptive reuse project prioritisation. Moreover, the priority aspects of the performance-based framework are interwoven, as shown in Fig. 1, towards promoting sustainable and resilient urban areas in New Zealand.

The adaptive reuse concept is a recommended intervention that lies at the core of the developed performance-based framework. The identified priority aspects that could contribute towards creating sustainable and resilient urban areas through the adaptive reuse approach are economic sustainability, built heritage preservation, socio-cultural aspects, building usability, and regulatory aspects. The economic sustainability aspect of the performance-based framework aims to increase local commercial activities, property and land value of nearby buildings, job creation, and revenue from tourism due to the potential new use of the historical building. Whereas built heritage preservation aims to promote historic and cultural development, the socio-cultural aspects target improvement in shared cultural identity, sense of belonging, the cultural significance of place, and the historical building's life cycle during an adaptive reuse decision-making process. Also, while the building usability aspect aims to minimise the obsolescence and high vacancy rate of the historical buildings through deliberations about target new use, potential users, and functionality of the historical building, the regulatory aspect aims to balance regulatory deliberations among relevant stakeholders to promote compliance to the building code, seismic, environmental health and safety, fire, emergency, and disability requirements of historical buildings.

However, some identified barriers that could constrain the adaptive reuse concept have been categorised under capital investment, building condition, and regulations (Bullen \& Love, 2011c), and fine-tuned to the New Zealand context. The barriers under capital investment include lack of historical building investors, poor marketability and corporate image of historical buildings, lack of incentives for historical building investors, low occupier demand of historical buildings, the high future value of underlying land, and high retrofit costs. Also, those under building conditions include location, residual service life, functionality, internal layout, structural integrity, and space utilisation of the existing historical building. Furthermore, the regulatory barriers include governance restrictions, seismic retrofit, zoning and planning, building code, heritage preservation, and health and safety regulatory requirements.

The decision-making processes of an adaptive reuse project prioritisation need to account for other aspects aside economic gains if a proper interpretation and assessment of the potentials of historical building alternatives are to be realised (Heath et al., 2013). Too much emphasis on only monetary issues could trigger a biased decisionmaking process (Langston, Wong, Hui, \& Shen, 2008). The financial return on investment is undeniably commonly connected to identifying value for money on adaptive reuse project development projects. Nevertheless, other relevant issues are beginning to become significant, especially for socio-cultural development projects towards urban regeneration. Issues such as building usability, built heritage preservation, socio-cultural, and regulatory aspects, for instance, could be even more essential when evaluating the social sustainability of a declining urban area. As no separate priority aspect or criterion can adequately address all complex issues in an adaptive reuse project prioritisation process, a multiple-criteria decision-making technique proposes a considerable benefit. Moreover, socio-cultural costs and benefits usually have lesser links to financial issues and do not have exponential depreciation in significance with time, hence, should not be discounted together with cash flows (Langston, 2013).

\section{Conclusions}

This paper presents the parameters for the development of a performance-based framework, to prioritise the most suitable historical building options for adaptive reuse intervention from a list of underutilised buildings. This research's innovation is projected for its future real-world application. The purpose is to provide more targeted and effective decision-making outcomes in situations where shrinking cities are faced with several options to evaluate the potentials of retaining their abundant historical buildings towards building sustainable and resilient urban areas. The developed performance-based framework is resourceful because it is designed to apply a multi-criteria methodology for validation. The validation exercise involved sifting through a local council's portfolio of underutilised historical building stock at an appropriate timing, to flag and evaluate the adaptive reuse potentials of the building against the five identified priority aspects in the performance-based framework. The implication of prioritising optimal historical building alternatives is that decision-makers could then concentrate on investing in adaptive reuse projects with the utmost potential added value to an immediate urban area.

This paper's performance-based framework identifies relevant parameters to be considered during adaptive reuse decision-making processes for urban regeneration while balancing diverse stakeholder's objectives to promote performance-based planning while prioritising optimal historical building alternatives. The identified parameters for the performance-based framework is recommended as both practical and reasonable while providing a range of values within known limits to facilitate the determination of prioritisations and rankings. The outcome of this study contributes to the enhancement of New Zealand's quest for attaining sustainable and resilient provincial urban areas through the retention of underutilised historical buildings. A limitation of this paper is that the parameters for the performance-based framework were identified within the context of underutilised historical buildings in New Zealand. However, it is very flexible for modification and application to all types of existing buildings in other areas, while carefully considering the contexts of each future applications to ensure the accuracy of the validation process. Another limitation of this paper is the use of only a focus group workshop for the validation process, due to its technical over-dependence on the number of participants involved in the focus group, their expertise around all the aspects included in the framework, their understanding of the complexities of the process and also their experience on adaptive reuse projects. The use of case studies or simulations methods would improve this shortcoming to facilitate the implementation of performance-based urban regeneration strategies, particularly in provincial areas. Accordingly, the performancebased framework has been validated with real-life case studies (Aigwi, Egbelakin, et al., 2019) to justify its appropriateness for use as a holistic approach to urban regeneration.

\section{Declaration of competing interest}

The authors declare that they have no known competing financial interests or personal relationships that could have appeared to influence the work reported in this paper. 


\section{Acknowledgements}

This study was (partially) supported by QuakeCoRE, a New Zealand Tertiary Education Commission-funded Centre. This is QuakeCoRE publication number 0573 .

\section{References}

Aigwi, I. E., Egbelakin, T., \& Ingham, J. (2018). Efficacy of adaptive reuse for the redevelopment of underutilised historical buildings: Towards the regeneration of New Zealand's provincial town centres. International Journal of Building Pathology and Adaptation, 36(4), 385-407.

Aigwi, I. E., Egbelakin, T., Ingham, J., Phipps, R., Rotimi, J., \& Filippova, O. (2019). A performance-based framework to prioritise underutilised historical buildings for adaptive reuse interventions in New Zealand. Sustainable Cities and Society, 48, 101547. https://doi.org/10.1016/j.scs.2019.101547.

Aigwi, I. E., Phipps, R., Ingham, J., \& Filippova, O. (2019). Urban transformation trajectories of New Zealand's earliest cities undergoing decline: Identifying links to the newly enforced Building (Earthquake-Prone b Buildings) Amendment Act 2016. Paper presented at the 43rd Australasian Universities Building Education Association (AUBEA) conference, 6-8 November, Noosa QLD, Australia.

Aigwi, I. E., Phipps, R., Ingham, J., \& Filippova, O. (2020). Characterisation of adaptive reuse stakeholders and the effectiveness of collaborative rationality towards building resilient urban areas. Systemic Practice and Action Research, 33(3), 1-11. https://doi. org/10.1007/s11213-020-09521-0.

Alexander, K. (2006). The application of usability concepts in the built environment. Journal of Facilities Management, 4(4), 262-270.

Alexander, K., Huovala, R., \& Kaya, S. (2003). Case study: NCR, Discovery Centre, Dundee. Draft report. CIB task group 51, usability of workplaces. University of Salford.

Alpopi, C., \& Manole, C. (2013). Integrated urban regeneration-solution for cities revitalize. Procedia Economics and Finance, 6, 178-185.

Arge, K. (2004). Forprosjekt.-effektiv bruk av arealer. (Note, NBI).

Baker, D. C., Sipe, N. G., \& Gleeson, B. J. (2006). Performance-based planning: Perspectives from the United States, Australia, and New Zealand. Journal of Planning Education and Research, 25(4), 396-409.

Baker, H., Moncaster, A., \& Al-Tabbaa, A. (2017). Decision-making for the demolition ot adaptation of buildings. Proceedings of the Institution of Civil Engineers: Forensic Engineering, 170, 144-156.

Baker, J. D. (2016). The purpose, process, and methods of writing a literature review. AORN Journal, 103(3), 265-269.

Ball, R. (1999). Developers, regeneration and sustainability issues in the reuse of vacant industrial buildings. Building Research \& Information, 27(3), 140-148.

Ball, R. (2002). Re use potential and vacant industrial premises: Revisiting the regeneration issue in Stoke-on-Trent. Journal of Property Research, 19(2), 93-110.

Bedate, A., Herrero, L. C., \& Sanz, J.Á. (2004). Economic valuation of the cultural heritage: Application to four case studies in Spain. Journal of Cultural Heritage, 5(1), $101-111$.

Binder, M. L. (2003). Adaptive reuse and sustainable design: A holistic approach for abandoned industrial buildings (Master's degree). Ohio: University of Cincinnat (ucin1053607193).

Boarin, P. (2016). Bridging the gap between environmental sustainability and heritage preservation: Towards a certified sustainable conservation, adaptation and retrofitting of historic buildings. Paper presented at the 50th International Conference of the Architectural Science Association (ANZASCA), 7-9 December, Adelaide.

Bromley, R. D., Tallon, A. R., \& Thomas, C. J. (2005). City centre regeneration through residential development: Contributing to sustainability. Urban Studies, 42(13), 2407-2429.

Bullen, P. A. (2007). Adaptive reuse and sustainability of commercial buildings. Facilities, 25(1/2), 20-31.

Bullen, P. A., \& Love, P. E. (2010). The rhetoric of adaptive reuse or reality of demolition: Views from the field. Cities, 27(4), 215-224.

Bullen, P. A., \& Love, P. E. (2011a). Adaptive reuse of heritage buildings. Structural Survey, 29(5), 411-421.

Bullen, P. A., \& Love, P. E. (2011b). Adaptive reuse of heritage buildings: Sustaining an icon or eyesore. Paper presented at the COBRA 2011 - Proceedings of RICS construction and property conference, UK.

Bullen, P. A., \& Love, P. E. (2011c). A new future for the past: A model for adaptive reuse decision-making. Built Environment Project and Asset Management, 1(1), 32-44.

Butina-Watson, G., \& Bentley, I. (2007). Identity by design. Oxford: Elsevier Ltd.

Caccavelli, D., \& Gugerli, H. (2002). TOBUS-A European diagnosis and decision-making tool for office building upgrading. Energy and Buildings, 34(2), 113-119.

Chau, K., Wong, S., Leung, A., \& Yiu, C. (2003). Estimating the value enhancement effects of refurbishment. Facilities, 21(1/2), 13-19.

Conejos, S., Chew, M. Y., \& Yung, E. H. (2017). The future adaptivity of nineteenth century heritage buildings. International Journal of Building Pathology and Adaptation, 35(4), 332-347.

Cook, S., \& Thomas, C. (2003). An alternative approach to examining the ripple effect in UK house prices. Applied Economics Letters, 10(13), 849-851.

CPWD (2013). Handbook on conservation heritage buildings. New Delhi: Central Public Works Department.

Douglas, J. (2006). Building adaptation (2nd ed.). London: Routledge.

Elsorady, D. A. (2014). Assessment of the compatibility of new uses for heritage buildings: The example of Alexandria National Museum, Alexandria, Egypt. Journal of Cultural
Heritage, 15(5), 511-521.

Engelhardt, R. A. \& Rogers, P. R. (2009). Hoi an protocols for best conservation practice in Asia: Professional guidelines for assuring and preserving the authenticity of heritage sites in the context of the cultures of Asia. (9292232428).

Engelhardt, R. A., Unakul, M. H., \& Endrina, E. (2007). Asia conserved: Lessons learned from the UNESCO Asia-Pacific heritage awards for culture heritage conservation (2000-2004): United Nations educational. Scientific Cultural Organization.

Ferretti, V., Bottero, M., \& Mondini, G. (2014). Decision making and cultural heritage: An application of the multi-attribute value theory for the reuse of historical buildings. Journal of Cultural Heritage, 15(6), 644-655.

Frew, T., Baker, D. C., \& Donehue, P. (2016). Performance based planning in Queensland: A case of unintended plan-making outcomes. Land Use Policy, 50, 239-251.

Geraedts, R. P., \& Van der Voordt, D. (2007). A tool to measure opportunities and risks of converting empty offices into dwellings. Paper presented at the proceedings of international conference sustainable urban areas, (25th-28th June), Rotterdam.

Goodwin, C., Tonks, G., \& Ingham, J. (2009). Identifying heritage value in URM buildings. SESOC Journal, 22(2), 16-28.

Gravagnuolo, A., Angrisano, M., \& Fusco Girard, L. (2019). Circular economy strategies in eight historic port cities: Criteria and indicators towards a circular city assessment framework. Sustainability, 11(13), 3512.

Gravagnuolo, A., Girard, L. F., Ost, C., \& Saleh, R. (2017). Evaluation criteria for a circular adaptive reuse of cultural heritage. BDC. Bollettino Del Centro Calza Bini, 17(2), $185-216$.

Green, B. N., Johnson, C. D., \& Adams, A. (2006). Writing narrative literature reviews for peer-reviewed journals: Secrets of the trade. Journal of Chiropractic Medicine, 5(3), $101-117$.

Heath, T. (2001). Adaptive re-use of offices for residential use: The experiences of London and Toronto. Cities, 18(3), 173-184.

Heath, T., Oc, T., \& Tiesdell, S. (2013). Revitalising historic urban quarters. Routledge.

Highfield, D., \& Gorse, C. (2009). Refurbishment and upgrading of buildings (2nd ed.). London: Routledge.

ICOMOS (1931). The Athens charter for the restoration of historic monuments. The first international congress architects and technicians of historic monuments. Athens: UNESCO.

ICOMOS (1964). The Venice charter: International charter for the conservation and restoration of monuments and sites. Venice ICOMOS.

ICOMOS (2013). The Burra charter: The Australia ICOMOS charter for places of cultural significance 1999: With associated guidelines and code on the ethics of co-existence. Burwood: Australia ICOMOS.

ICOMOS (Ed.). (2019). The Paris charter: The future of our pasts - engaging cultural heritage in climate action (ICOMOS Ed.). Paris ICOMOS.

Itard, L., \& Klunder, G. (2007). Comparing environmental impacts of renovated housing stock with new construction. Building Research \& Information, 35(3), 252-267.

Jensø, M., Hansen, G. K., \& Haugen, T. I. (2004). Usability of buildings: Theoretical framework for understanding and exploring usability of buildings. Facilities Management and Maintenence, 225.

Kohler, N., \& Yang, W. (2007). Long-term management of building stocks. Building Research \& Information, 35(4), 351-362.

Koren, H., \& Butler, C. (2006). The interconnection between the built environment ecology and health. Environmental security and environmental management: The role of risk assessment (pp. 111-125). Dordrecht: Springer.

Langston, C. (2013). Life-cost approach to building evaluation. Routledge.

Langston, C., \& Shen, L. Y. (2007). Application of the adaptive reuse potential model in Hong Kong: A case study of Lui Seng Chun. International Journal of Strategic Property Management, 11(4), 193-207.

Langston, C., \& Smith, J. (2012). Modelling property management decisions using 'iconCUR'. Automation in Construction, 22, 406-413.

Langston, C., Wong, F. K., Hui, E. C., \& Shen, L.-Y. (2007). Strategic assessment of building adaptive reuse opportunities in Hong Kong. Building and Environment, 43(10), 1709-1718.

Langston, C., Wong, F. K., Hui, E. C., \& Shen, L.-Y. (2008). Strategic assessment of building adaptive reuse opportunities in Hong Kong. Building and Environment, 43(10), 1709-1718.

Larkham, P. (2002). Conservation and the city. New York: Routledge.

Love, P., \& Bullen, P. (2009). Toward the sustainable adaptation of existing facilities. Facilities, 27(9/10), 357-367.

Machi, L. A., \& McEvoy, B. T. (2016). The literature review: Six steps to success. California: Corwin Press.

Mansfield, J. R. (2002). What's in a name? Complexities in the definition of "refurbishment". Property Management, 20(1), 23-30.

Mason, R. (2009). Reclaiming the history of places. Local planning: Contemporary principles and practice (pp. 127-133). .

MBIE (2016). Building performance: Managing earthquake-prone buildings. Retrieved from https://www.building.govt.nz/managing-buildings/managing-earthquakeprone-buildings/resources

McCormick, B. (2002). Factory Chic: Reusing Wisconsin's Historic Industrial Buildings. The Wisconsin Magazine of History, 85(3), 42-45.

Mısırlısoy, D., \& Günçe, K. (2016a). Adaptive reuse strategies for heritage buildings: A holistic approach. Sustainable Cities and Society, 26, 91-98.

Misirlısoy, D., \& Günce, K. (2016b). A critical look to the adaptive reuse of traditional urban houses in the Walled City of Nicosia. Journal of Architectural Conservation, 22(2), 149-166.

Murtagh, W. J. (2006). Keeping time: The history and theory of preservation in America. New Jersey, United States: John Wiley \& Sons.

Nasser, N. (2003). Planning for urban heritage places: Reconciling conservation, tourism, and sustainable development. Journal of Planning Literature, 17(4), 467-479.

Navrud, S., \& Ready, R. C. (2002). Valuing cultural heritage: Applying environmental 
valuation techniques to historic buildings, monuments and artifacts. Edward Elgar Publishing.

NSW, \& RAIA (2008). New uses for heritage places: Guidelines for the adaptation of historic buildings and sites. Sydney: Joint Publication of the Heritage council of New South Wales and the Royal Australian Institute of Architects.

O'Donnell, C. (2004). Getting serious about green dollars. Property Australia, 18(4), 1-2. Retrieved from http://www.propertycouncil.com.au/.

Onwuegbuzie, A. J., \& Frels, R. (2016). Seven steps to a comprehensive literature review: A multimodal and cultural approach. London: Sage.

Orbasli, A. (2002). Tourists in historic towns: Urban conservation and heritage management. Taylor \& Francis.

Pearce, A. R., DuBose, J. R., \& Vanegas, J. A. (2004). Rehabilitation as a strategy to increase the sustainability of the built environment. Atlanta: School of Civil and Environmental Engineering, Georgia Institute of Technology.

Pedersen, A. (2002). Managing tourism at world heritage sites. Paris: UNESCO.

Plevoets, B., \& Van Cleempoel, K. (2011). Adaptive reuse as a strategy towards conservation of cultural heritage: A literature review. Structural studies, repairs and maintenance of heritage architecture XII. 118. Structural studies, repairs and maintenance of heritage architecture XII (pp. 155-163).

Plevoets, B., \& Van Cleempoel, K. (2019). Adaptive reuse of the built heritage: Concepts and cases of an emerging discipline. Routledge.

Rohracher, H. (2001). Managing the technological transition to sustainable construction of buildings: A socio-technical perspective. Technology Analysis \& Strategic Management, 13(1), 137-150.

Shehata, W. T. A., Moustafa, Y., Sherif, L., \& Botros, A. (2015). Towards the comprehensive and systematic assessment of the adaptive reuse of Islamic architectural heritage in Cairo: A conceptual framework. Journal of Cultural Heritage Management and Sustainable Development, 5(1), 14-29.

Shipley, R., Utz, S., \& Parsons, M. (2006). Does adaptive reuse pay? A study of the business of building renovation in Ontario, Canada. International Journal of Heritage Studies, 12(6), 505-520.

UNESCO (2009). UNESCO World Heritage Centre - Official site [online], United Nations. Retrieved from http://whc.unesco.org/en/about/.
Wang, H.-J., \& Zeng, Z.-T. (2010). A multi-objective decision-making process for reuse selection of historic buildings. Expert Systems with Applications, 37(2), 1241-1249.

Wilkinson, S., James, K., \& Reed, R. (2009). Using building adaptation to deliver sustainability in Australia. Structural Survey, 27(1), 46-61.

Wilkinson, S., \& Osmond, P. (2018). Building resilience in urban settlements. International Journal of Building Pathology and Adaptation, 36(4), 334-336.

Wilkinson, S., \& Remøy, H. (2018). Building urban resilience through change of use. John Wiley \& Sons.

Wilkinson, S., Remøy, H., \& Langston, C. (2014). Sustainable building adaptation: Innovations in decision-making. John Wiley \& Sons.

Wilkinson, S., \& Remoy, H. T. (2011). Sustainability and within use office building adaptations: A comparison of Dutch and Australian practices. Paper presented at the PRRES 2011: Proceedings of the 17th Pacific rim real estate society annual conference.

Wilson, C. (2010). Adaptive reuse of industrial buildings in Toronto, Ontario: Evaluating criteria for determining building selection.

Wong, L. (2017). Adaptive reuse: Extending the lives of buildings. Basel: Birkhäuser.

Yakubu, I. E., Egbelakin, T., Dizhur, D., Ingham, J., Sungho Park, K., \& Phipps, R. (2017). Why are older inner-city buildings vacant? Implications for town centre regeneration. Journal of Urban Regeneration \& Renewal, 11(1), 44-59.

Yau, Y., Wing Chau, K., Chi Wing Ho, D., \& Kei Wong, S. (2008). An empirical study on the positive externality of building refurbishment. International journal of housing markets and analysis, 1(1), 19-32.

Yildirim, M. (2012). Assessment of the decision-making process for re-use of a historical asset: The example of Diyarbakir Hasan Pasha Khan, Turkey. Journal of Cultural Heritage, 13(4), 379-388.

Yiu, C., \& Leung, A. Y. (2005). A cost-and-benefit evaluation of housing rehabilitation. Structural Survey, 23(2), 138-151.

Yuan, H., Shen, L., Hao, J. J., \& Lu, W. (2011). A model for cost-benefit analysis of construction and demolition waste management throughout the waste chain. Resources, Conservation and Recycling, 55(6), 604-612.

Yung, E. H., \& Chan, E. H. (2012). Implementation challenges to the adaptive reuse of heritage buildings: Towards the goals of sustainable, low carbon cities. Habitat International, 36(3), 352-361. 